\title{
Robotic and standard surgical intervention as adjunct therapies for retroperitoneal ganglioneuroma resection: a case report
}

Wagner M. Tavares ${ }^{1,2}$, Sabrina Araujo de Franca ${ }^{1 *} \mathbb{D}$, Amsterdam S. Vasconcelos ${ }^{3}$, David S. L. Parra', Sergio R. R. Araújo ${ }^{4}$ and Manoel J. Teixeira ${ }^{2}$

\begin{abstract}
Background: Ganglioneuroma (GN) is ranked by the International Neuroblastoma Pathology Classification as a benign tumor. It can occur anywhere along the sympathetic nerve chain and surgical excision is the treatment of choice.

Case presentation: An 18-year-old female patient sought medical assistance after 6 months of constant dorsal and back pain radiating from the thoracic region to the right abdominal flank. Magnetic resonance imaging revealed a solid nodular lesion with heterogeneous post-contrast enhancement and lobulated contours, centered on the right foramina of D12-L1, with a projection to the intracanal space, which compressed and laterally displaced the dural sac and had a right paravertebral extension between the vertebral bodies of D11 and superior aspect of L2. Ganglioneuroma was diagnosed using immunohistochemical analysis. It was decided to use a surgical approach in two stages: robot assisted for the anterior/retroperitoneal mass and a posterior hemilaminectomy/microsurgical approach to attempt total resection, avoiding the traditional anterior thoracoabdominal surgical incision and optimizing the patient's postoperative outcomes. No postoperative adverse events were noted, and the patient was discharged on postoperative day 5.
\end{abstract}

Conclusion: This retroperitoneal GN presentation was peculiar because it originated at the D12 nerve root, which extended to the retroperitoneal space and inside the spinal canal. We hope that our case report can assist future decisions in similar circumstances.

Keywords: Adjunct surgery, Case report, Ganglioneuroma, Retroperitoneal, Robotic assisted surgery

\section{Background}

Ganglioneuroma (GN) is the most mature form of a peripheral neuroblastic tumor $[1,2]$, i.e., an embryonic tumor of the sympathetic nervous system [2]. Histologically, it has a Schwannian rich stroma, with a low mitotickaryorrhexis index, and few immature neuroblasts cells,

\footnotetext{
*Correspondence: pesquisacientifica@ipspac.org.br

${ }^{1}$ Department of Research of IPSPAC, Instituto Paulista de Saúde Para Alta Complexidade, 199 Padre Anchieta Avenue, Room 2, Jardim, Santo André, SP 09090-710, Brazil

Full list of author information is available at the end of the article
}

which the International Neuroblastoma Pathology Classification $[3,4]$ ranks as histologically benign.

GNs can occur anywhere along the sympathetic nerve chain and commonly at the mediastinum, retroperitoneum, and adrenal glands [5]. Surgical excision is the treatment of choice.

Here, we describe the case of an 18-year-old female patient with retroperitoneal $\mathrm{GN}$, which was surgically removed. The time elapsed between first consult and surgical intervention was four months. In addition to the tumor's rarity, this case is of special interest because 
of the associated pathologic presentation of a retroperitoneal mass with spinal invasion and the innovative combination of robot-assisted surgery with a traditional neurosurgical approach.

\section{Case presentation}

An 18-year-old female patient, with uneventful past medical history and no relevant family history, reported constant dorsal and back pain radiating from the thoracic region to the right abdominal flank for 6 months. Pain worsened at physical exertion. The pain was initially treated with anti-inflammatory drugs and analgesics, with a good response for 2 weeks, after which, it became progressively resistant to medication. The patient provided informed written consent that was approved by the IPSPAC Institutional Review Board.

\section{Imaging and clinical findings}

Patients neurologic evaluation revealed decreased touch and pain perception between the T7 and T11 dermatomes. Reflexes, muscle strength, and laboratory results were normal.

Gadolinium-enhanced spine magnetic resonance imaging (MRI) revealed a solid nodular lesion with heterogeneous post-contrast enhancement and lobulated contours centered on the right foramina of D12-L1, with a projection to the intracanal space, which compressed and laterally displaced the dural sac having a right paravertebral extension between the vertebral bodies of D11 and superior aspect of L2. It measured

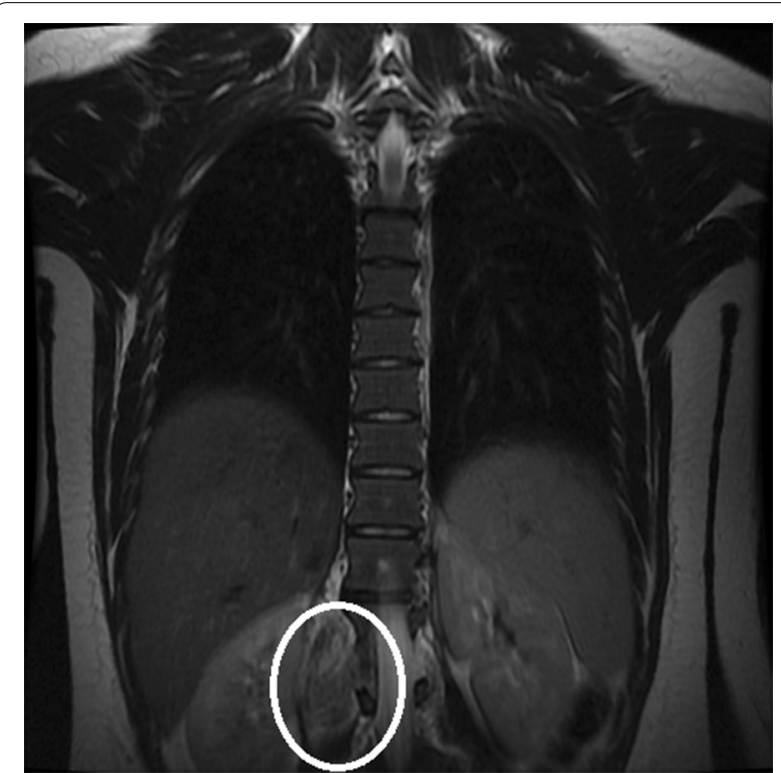

Fig. 1 Coronal T2 magnetic resonance imaging. Circle: solid nodular lesion approximately $5.0 \times 3.0 \times 9.5 \mathrm{~cm}$ (latero-lateral $\times$ anteroposterior $\times$ caudocranial) $\quad$ (Fig. 1). Subsequently, the patient underwent guided biopsy with computed tomography that was histologically described as a focal fusocellular proliferation with dissociating skeletal-muscle fibers (Figs. 2, 3), and the immunohistochemical I191289 study confirmed it as a Schwannoma. However, as the MRI and immunohistochemical analysis [that was positive for S100 protein and (SRY (sex determining region Y)-box 10) (SOX-10) antigens] could suggest other diagnoses, we performed a lamina revision in a second pathology laboratory, which confirmed a diagnosis of GN.

After lamina revision, the patient quickly deteriorated with bladder dysfunction and worsening muscle strength on the proximal right lower limb, leading to an expedite surgical intervention conducted by neurosurgery and oncology team.

\section{Surgical procedure}

Surgical intervention was planned through a combination of two approaches: robot assisted for the anterior/

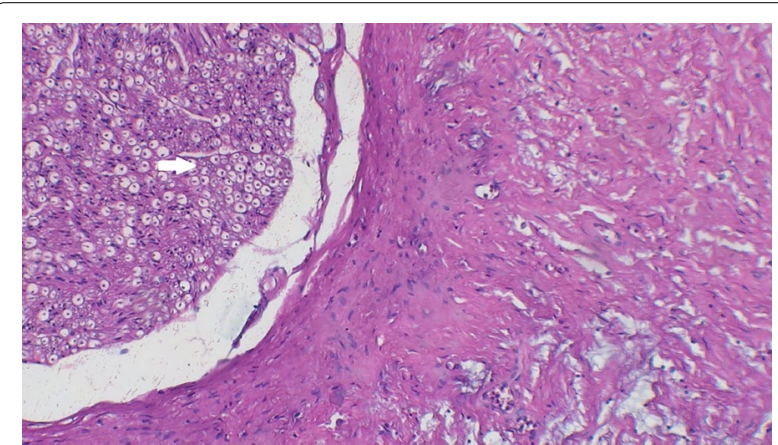

Fig. 2 Fibrillar proliferation with a Schwannian pattern next to a nerve segment (arrow). Hematoxylin and eosin staining at $20 \times$ magnification

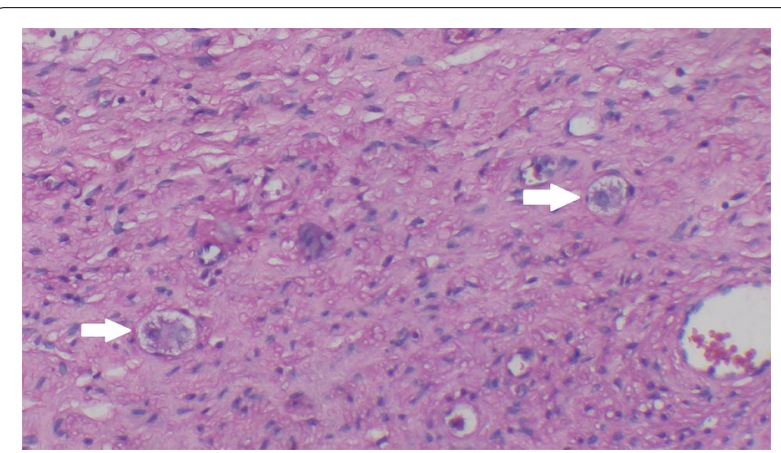

Fig. 3 Ganglion cells (arrow). Hematoxylin and eosin staining at $40 \times$ magnification. Superior long axis T2 fast spin echo imaging. Arrow: solid nodular lesion. 
retroperitoneal stage and a posterior hemilaminectomy/ microsurgical approach to attempt total resection.

The anterior access was performed as a right robotassisted lateral transabdominal adrenalectomy using the da Vinci ${ }^{\circledR}$ Xi surgical system (Intuitive Surgical, Sunnyville, CA, USA). Preoperative preparation, patient positioning, and port-site access followed the lateral transabdominal laparoscopic adrenalectomy protocol. The patient was placed in the left lateral decubitus position and five trocars were inserted: an 8-mm camera port was inserted midway between the umbilicus and the right costal margin $20 \mathrm{~cm}$ away from the target; two robotic instrument ports, both $8 \mathrm{~mm}$, were inserted along a line two fingerbreadths $8 \mathrm{~cm}$ away from each other over the umbilicus; one robotic instrument $8-\mathrm{mm}$ port was inserted along the same line under the umbilicus at the right iliac pit away from the 8-cm camera port; a 5-mm liver retraction port was inserted in the midline in the epigastrium, and an accessory 10/12 $\mathrm{mm}$ auxiliary port was inserted between the camera port and right iliac pit port $7 \mathrm{~cm}$ away from each other. The four-step technique of robotic right adrenalectomy was applied [6]: (1) complete division of the hepatocolic ligament; (2) delineation of the right adreno-caval junction; (3) division of the right adrenal vein; (4) adrenal separation from the kidney, retroperitoneal approach in retrocaval space dissection and identification of the tumor circumferentially. Thus, after first robotic exploration, the triangular ligament was divided via a robotic monopolar hook. The right lobe of the liver was retracted with a laparoscopic retractor (Additional file 1: Video S1), and the inferior vena cava was exposed after the inferior to superior peritonectomy. The surgeon at the console used the robotic hook for precise dissection of the vena cava along its lateral edge between the inferior vena cava and liver. Landmarks identified included laterally the superior pole of the right kidney and posteriorly the psoas muscle. After careful dissection (Additional file 2: Video S2), a yellowish, fibroelastic, well encapsulated mass was identified adjacent to the periadrenal space. It lousily adhered to the adjacent structures and could be thoroughly isolated. The surgeon performed the laparoscopic suturing of the diaphragm (Additional file 3: Video S3) before fully dissect the anterior portion, which was successful until the right limit of the D12 vertebra.

Afterward the anterior step was performed, the patient was positioned in ventral decubitus position and prepared for a traditional laminectomy. After a dorsolumbar medial incision, a regular bilateral paraspinal muscular dissection was performed. The D11, D12, and L1 lamina, facets, and transverse process were exposed. After performing a D11-L1 hemilaminectomy, the tumor's origin was identified from the D12 nerve root. The tumor extended from the retroperitoneal space to the spinal canal, entering from the D12-L1 right foramina and compressing the dura mater. Following the reclamation of the D11-D12 zygapophyseal facet and D12 transverse process, the posterior intracanal and paravertebral elements of the mass were removed under microscope visualization. The D12 nerve root had to be severed for total tumor removal; afterward, the retroperitoneal space could be recognized. Postoperative pathologic examination confirmed that it was a GN. Figure 4 demonstrates the patient before and after tumor removal.

\section{Postoperative course}

Postoperatively, the patient recovered well. On postoperative day 1, the patient experienced episodes of muscle pain in the abdominal wall and laminectomy region, controlled with analgesics and no further investigation was needed. Patient mobilization occurred on postoperative day 2 , when the patient could walk with assistance. The patient was discharged on postoperative day 5 . After 1-year of follow-up, the patient had improved muscle strength but still experienced episodes of myofascial pain in the dorsum and on the right lateral abdominal flank, again controlled with analgesics. However, she did not adhere to her physical rehabilitation protocol.

\section{Discussion and conclusions}

GNs are rare benign neurogenic (ganglion cell) tumors, commonly affecting adolescents and youth adults $[7,8]$. Although GNs usually develop in childhood, adult detection can be explained by their slow asymptomatic growth [9-11], justifying the delay in seeking medical assistance [12].

Retroperitoneal GN commonly presents local masseffect symptoms, leading to an often casual diagnosis [5, $11,13]$. In our case, the patient sought medical assistance because of secondary symptoms (dorsal and back pain radiating to the abdominal flank), explained by the local mass-effect compression at D12-L1, which laterally displaced the dural sac, decreasing touch and pain perception between the T7 and T11 dermatomes.

GN is also distinguished by the increased production of catecholamines, with Verner-Morrison syndrome as the recurrent example of this endocrine dysregulation. [8, $12,14,15]$ However, this phenomenon rarely emerges in mature GNs [9].

Cai et al. [16] reported on 17 patients with retroperitoneal GN, of whom, 13 did not present obvious clinical symptoms or signs. Four patients had palpable masses, hypertension, or diarrhea. Our patient did not mention or presented with symptoms of diarrhea, sweating, or hypertension, leading us to conclude that this could be a 

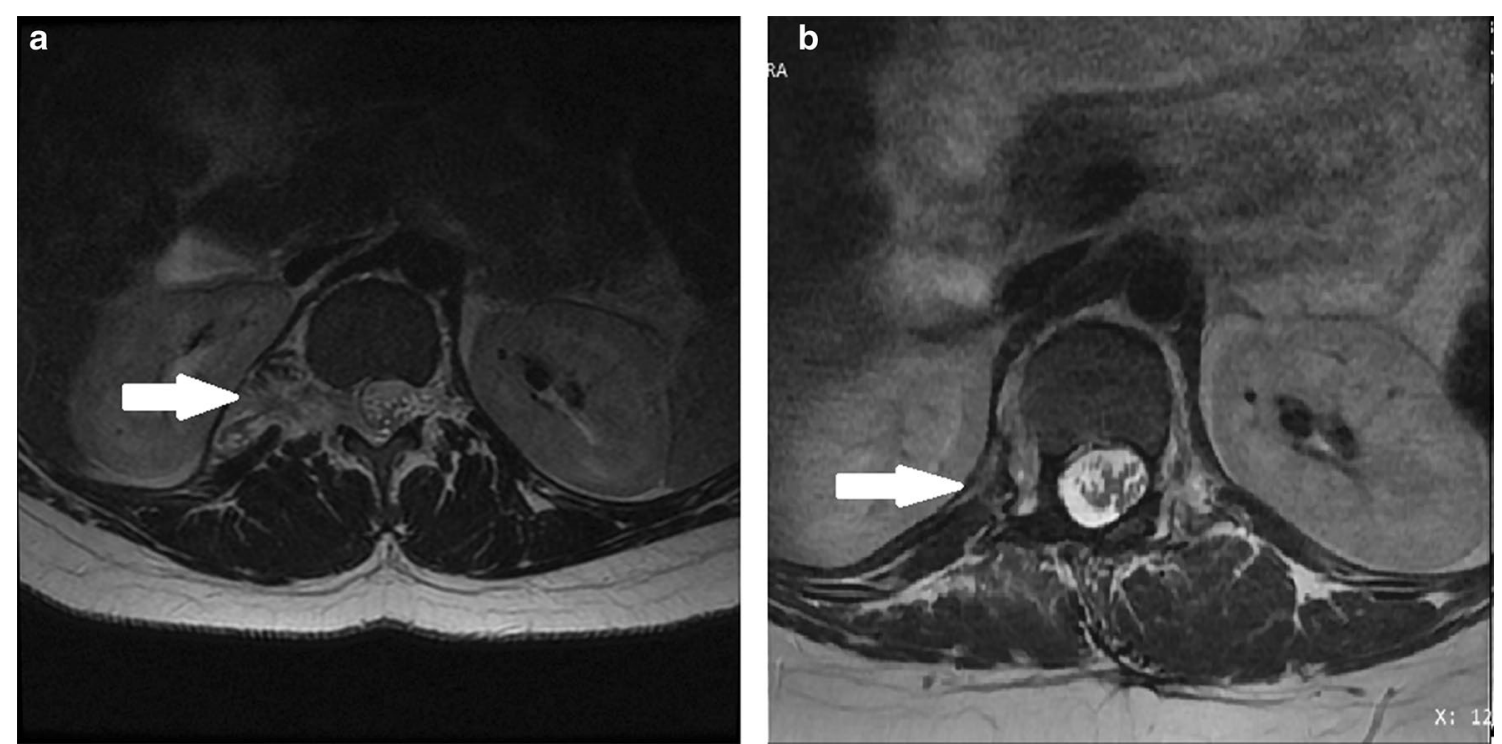

Fig. 4 Superior long axis T2 fast spin echo imaging. Arrow: solid nodular lesion. a Before surgery. b After surgery

mature GN. Later bladder dysfunction is also observed in lower thoracic or lumbar GNs [12].

Preoperative diagnosis predominantly relies on imaging techniques. Reported imaging findings $[7,8,17]$ include extensive calcifications with most cases being well-circumcised nondescript homogenous masses, similar to our case. Calcifications are secondary specific histologic features of neuroblastic tumors [2, 18], being present in up to $60 \%$ of cases $[19,20]$. In GNs, calcification is normally discrete and punctuate, different from that in neuroblastomas (coarse, amorphous, and mottled) and ganglioneuroblastomas (granular) [21]. Careful examination of all laminas is necessary to avoid overlooking small calcification foci [2].

Considering the indefinite diagnosis suggested by the imaging examination, a biopsy and/or excision for histopathological examination is frequently performed. Besides the level of cellular maturity, distinct between malignant neuroblastic (neuroblastoma and ganglioneuroblastoma) tumors and GNs is the presence of hemorrhage, metastasis, and necrosis in malignant presentations [22].

The International Neuroblastoma Pathology Committee [2] standardized the criteria for GN histologic diagnosis, defined by the predominant composition of a ganglioneuromatous stroma with an insignificant component of mature ganglion cells (Fig. 4). For such anatomic sites, GN should be the diagnosis of choice, because of the neurofibroma-like lesion, whether or not ganglion cells are identified [7]. In the retroperitoneum, Schwannoma cells are usually more cellular, with larger plump spin cells, showing diffused and strong expression of S-100 protein [7, 17], which was present in our patient's histopathological results. Likewise, greater expression of SOX-10, which is correlated with glial differentiation, has been found in GNs [23]. Our histopathological specimen was pre- and postoperatively positive for SOX-10.

Although partial or no resection can be accepted as a GN treatment [24, 25], the long-term prognosis is improved with total resection, and recurrence surveillance can be made through image control $[10,26]$. In our case, total resection was achieved by association of two surgical techniques: robot-assisted lateral transabdominal and posterior laminectomy. During surgical excision, it was noticed that the tumor originated from the nerve root, which is unusual for GNs with only few cases described in the literature $[10,24,25,27,28]$.

Nevertheless, to our knowledge, no other case treatment was as innovative as the association of these two surgical techniques. The traditional option for removing a retroperitoneal mass would involve an extensive thoracoabdominal surgical incision, such as in adrenalectomy procedures. In such cases, open surgery can result in higher doses of analgesics [29-31], greater blood loss [30, 32], increased hospital stay [29-33], and delay in return to normal activities [29, 31-33]. The combined robot-assisted method was selected because of the mass size and presumed benignancy, offering more advantages regarding invasiveness and postoperative recovery outcomes. We hope that our case report can assist future decisions in similar circumstances. 


\section{Abbreviations}

CM: Centimeter; GN: Ganglioneuroma; MM: Millimeter; MRI: Magnetic resonance imagining; SRY: Sex determining region Y; SOX-10: SRY-box 10.

\section{Supplementary Information}

The online version contains supplementary material available at https://doi. org/10.1186/s12893-021-01146-x.

Additional file 1: Video S1. Video that demonstrates liver retraction.mp4. Additional file 2: Video S2. Video that demonstrates tumor dissection. mp4

Additional file 3: Video S3. Video that demonstrates laparoscopic suturing of the diaphragm.mp4.

\section{Acknowledgements}

Not applicable.

\section{Authors' contributions}

All authors read and approved the final manuscript. WMT designed, analyzed, interpreted, wrote, and organize study elements. WMT and DSLP performed posterior hemilaminectomy/microsurgical. SAF and MJT analyzed, interpreted, wrote, and organize study elements. ASV provided recorded surgery and performed anterior robotic surgery. SRRA performed the histological examination.

\section{Funding}

The authors declare no source of funding.

\section{Availability of data and materials}

Data and materials are available upon request by contacting the corresponding author Sabrina Araujo de Franca. ORCID: 0000-0003-2682-4537, IPSPAC — Instituto Paulista de Saúde para a Alta Complexidade, 199 Padre Anchieta Avenue-Room 2, Jardim, Santo Andre, SP, 09090-710, Brazil; E-mail: pesquisacientifica@ipspac.org.br; Telephone:+1 (514) 804-1006.

\section{Declarations}

\section{Ethics approval and consent to participate}

The patient provided informed written consent that was approved by the Institutional Review Board.

\section{Consent for publication}

The informed written consent and this study were approved by the Instituto Paulista de Saúde para Alta Complexidade (IPSPAC) research ethics committee.

\section{Competing interests}

The authors declare that they have no competing interests.

\section{Author details}

${ }^{1}$ Department of Research of IPSPAC, Instituto Paulista de Saúde Para Alta Complexidade, 199 Padre Anchieta Avenue, Room 2, Jardim, Santo André, SP 09090-710, Brazil. ${ }^{2}$ Institute of Neurology, University of São Paulo, 255 Dr. Enéas de Carvalho Aguiar avenue, Cerqueira César, São Paulo, SP 05403-900, Brazil. ${ }^{3}$ Surgical Oncology Department, Hospital Santa Catarina, 200 Paulista Avenue, Bela Vista, São Paulo, SP 01310-000, Brazil. ${ }^{4}$ LabPac, Laboratório Anatomia Patológica Imuno-Histoquímica Citopatologica, 75 Calixto da Mota Street, Vila Mariana, São Paulo, SP 04117-100, Brazil.

Received: 7 January 2021 Accepted: 10 March 2021

Published online: 19 March 2021

\section{References}

1. Okamatsu C, London WB, Naranjo A, et al. Clinicopathological characteristics of ganglioneuroma and ganglioneuroblastoma: a report from the CCG and COG. Pediatr Blood Cancer. 2009;53:563-9. https://doi. org/10.1002/pbc.22106.

2. Shimada H, Ambros IM, Dehner LP, et al. Terminology and morphologic criteria of neuroblastic tumors. Cancer. 1999;86:349-63. https:// doi.org/10.1002/(SICI)1097-0142(19990715)86:2\%3c349::AID-CNCR2 0\%3e3.0.CO;2-Y.

3. Shimada $H$, Ambros IM, Dehner LP, et al. The international neuroblastoma pathology classification (the Shimada system). Cancer. 1999;86:364-72. https://doi.org/10.1002/(SICI)1097-0142(19990715)86:2\%3c364:.AIDCNCR21\%3e3.0.CO;2-7.

4. Peuchmaur M, D'Amore ESG, Joshi W, et al. Revision of the international neuroblastoma pathology classification. Cancer. 2003;98:2274-81. https :/doi.org/10.1002/cncr.11773.

5. Gilchrist JM, Donahue JE (2018) Peripheral nerve tumors. In: UpToDate, Post TW. Waltham

6. Krane LS, Shrivastava A, Eun D, et al. A four-step technique of robotic right adrenalectomy: initial experience. BJU Int. 2008;101:1289-92. https://doi. org/10.1111/j.1464-410X.2008.07433.x.

7. Mariño-Enríquez A, Hornick JL. Ganglioneuroma. In: Hornick J, editor. Practical soft tissue pathology: a diagnostic approach. A volume in the pattern recognition series. 2nd ed. Elsevier; 2018. p. 63-4.

8. Rodriguez FJ, Giannini C, Spinner RJ, Perry A. Miscellaneous benign neurogenic tumors. In: Hornick J, editor. Practical soft tissue pathology: a diagnostic approach. A volume in the pattern recognition series. 2nd ed. Elsevier; 2018. p. 357-9.

9. Kumar S, Singh S, Chandna A. Organ preservation in a case of retroperitoneal ganglioneuroma: a case report and review of literature. Case Rep Surg. 2016;2016:1-5. https://doi.org/10.1155/2016/6597374.

10. Mardi K, Thakur RC, Biswas B. Ganglioneuroma arising from the L5 nerve root: a rare case report. Asian J Neurosurg. 2015;10:232. https://doi. org/10.4103/1793-5482.161180

11. Pang BC, Lim CCT, Tan KK. Giant spinal ganglioneuroma-Journal of Clinical Neuroscience. J Clin Neurosci. 2005;12:967-72. https://doi. org/10.1016/j.jocn.2004.10.017.

12. Shephard $\mathrm{RH}$, Sutton $\mathrm{D}$. Dumb-bell ganglioneuromata of the spine with a report of four cases. Br J Surg. 1958;45:305-17. https://doi.org/10.1002/ bjs.18004519202.

13. Moriwaki Y, Miyake M, Yamamoto T, et al. Retroperitoneal ganglioneuroma: a case report and review of the Japanese literature. Intern Med. 1992;31:82-5. https://doi.org/10.2169/internalmedicine.31.82.

14. Geoerger B, Hero B, Harms D, et al. Metabolic activity and clinical features of primary ganglioneuromas. Cancer. 2001;91:1905-13. https :/doi.org/10.1002/1097-0142(20010515)91:10\%3c1905::AID-CNCR1 213\%3e3.0.CO;2-4.

15. Hayes FA, Green AA, Rao BN. Clinical manifestations of ganglioneuroma. Cancer. 1989;63:1211-4. https://doi.org/10.1002/1097-0142(19890 315)63:6\%3c1211::AID-CNCR2820630628\%3e3.0.CO;2-1.

16. Cai J, Zeng $\mathrm{Y}$, Zheng $\mathrm{H}$, et al. Retroperitoneal ganglioneuroma in children: CT and MRI features with histologic correlation. Eur J Radiol. 2010;75:31520. https://doi.org/10.1016/j.ejrad.2010.05.040

17. Skovronsky DM, Oberholtzer JC. Pathologic classification of peripheral nerve tumors. Neurosurg Clin N Am. 2004;15:157-66. https://doi. org/10.1016/j.nec.2004.02.005.

18. Lonergan GJ, Schwab CM, Suarez ES, Carlson CL. Neuroblastoma, ganglioneuroblastoma, and ganglioneuroma: radiologic-pathologic correlation. Radiogr Rev Publ Radiol Soc North Am Inc. 2002;22:911-34. https://doi. org/10.1148/radiographics.22.4.g02jl15911.

19. Wang F, Liu J, Zhang R, et al. CT and MRI of adrenal gland pathologies. Quant Imaging Med Surg. 2018;8:853-75. https://doi.org/10.21037/ qims.2018.09.13.

20. Ichikawa T, Ohtomo K, Araki T, et al. Ganglioneuroma: computed tomography and magnetic resonance features. Br J Radiol. 1996;69:114-21. https://doi.org/10.1259/0007-1285-69-818-114.

21. Rha SE, Byun JY, Jung SE, et al. Neurogenic tumors in the abdomen: tumor types and imaging characteristics. Radiographics. 2003;23:29-43. https://doi.org/10.1148/rg.231025050.

22. Manning MA, Srivastava A, Paal EE, et al. Nonepithelial neoplasms of the pancreas: radiologic-pathologic correlation, Part 1-benign tumors. Radiographics. 2016;36:123-41. https://doi.org/10.1148/rg.2016150212.

23. Gershon TR, Oppenheimer O, Chin SS, Gerald WL. Temporally regulated neural crest transcription factors distinguish neuroectodermal tumors of 
varying malignancy and differentiation. Neoplasia. 2005;7:575-84. https ://doi.org/10.1593/neo.04637.

24. Shrestha P, Singh AM, Adhikari RB, et al. Ganglioneuroma of spinal nerve root: a rare case mimicking herniated lumbar disc and cumbar radiculopathy. Hiroshima J Med Sci. 2016;65:61-3.

25. Jeong M, Lee S, Bin JK, et al. Ganglioneuroma of lumbar nerve root: a case report. J Korean Soc Radiol. 2013;68:153. https://doi.org/10.3348/ jkst.2013.68.2.153.

26. Mounasamy V, Thacker MM, Humble S, et al. Ganglioneuromas of the sacrum - a report of two cases with radiologic - pathologic correlation. Skeletal Radiol. 2006;35:117-21. https://doi.org/10.1007/s0025 6-005-0028-6.

27. Tsai FJ, Kuo KL, Tzou RD, et al. A huge extradural ganglioneuroma of the lumbar spine. Formos J Surg. 2014;47:160-5. https://doi.org/10.1016/j. fjs.2014.04.001.

28. Uchida K, Kobayashi S, Kubota C, et al. Microsurgical excision of ganglioneuroma arising from the C8 nerve root within the neuroforamen. Minim Invasive Neurosurg. 2007;50:350-4. https://doi. org/10.1055/s-2007-993207.

29. Barreca M, Presenti L, Renzi C, et al. Expectations and outcomes when moving from open to laparoscopic adrenalectomy: multivariate analysis. World J Surg. 2003;27:223-8. https://doi.org/10.1007/s00268-002-6474-6.
30. Bin YH, Al Zahrani A, Ahmed M, et al. Laparoscopic vs. open adrenalectomy: experience at king faisal specialist hospital and research centre. Riyadh Ann Saudi Med. 2003;23:36-8. https://doi. org/10.5144/0256-4947.2003.36.

31. Stefanidis D, Goldfarb M, Kercher KW, et al. SAGES guidelines for minimally invasive treatment of adrenal pathology. Surg Endosc. 2013;27:3960-80. https://doi.org/10.1007/s00464-013-3169-z.

32. Wang H-S, Li C-C, Chou Y-H, et al. Comparison of laparoscopic adrenalectomy with open surgery for adrenal tumors. Kaohsiung J Med Sci. 2009;25:438-44. https://doi.org/10.1016/S1607-551X(09)70539-X.

33. Autorino R, Bove P, De Sio M, et al. Open versus laparoscopic adrenalectomy for adrenocortical carcinoma: a meta-analysis of surgical and oncological outcomes. Ann Surg Oncol. 2016;23:1195-202. https://doi. org/10.1245/s10434-015-4900-x.

\section{Publisher's Note}

Springer Nature remains neutral with regard to jurisdictional claims in published maps and institutional affiliations.
Ready to submit your research? Choose BMC and benefit from:

- fast, convenient online submission

- thorough peer review by experienced researchers in your field

- rapid publication on acceptance

- support for research data, including large and complex data types

- gold Open Access which fosters wider collaboration and increased citations

- maximum visibility for your research: over 100M website views per year

At BMC, research is always in progress.

Learn more biomedcentral.com/submissions 